\title{
Physical characteristics of photon and electron beams from a radiotherapy accelerator
}

\author{
Varatharaj $C^{1}$, Shwetha $B^{1}$, Rekha Reddy $B^{2}$, Ravikumar $M^{3}$, S. Sathiyan ${ }^{4}$, Ganesh K. $M^{3}$ \\ ${ }^{1}$ Assistant Professor of Radiation Physics, ${ }^{2}$ Resident Physicist, ${ }^{3}$ Professor of Radiation Physics, ${ }^{4}$ Associate Professor of \\ Radiation Physics, all authors are affiliated with Department of Radiation Physics, Kidwai Memorial, Institute of \\ Oncology, Hosur Road, Bangalore, Karnataka, India.
}

Address for correspondence: Dr Varatharaj C, Email: drvaratharaj@gmail.com

\begin{abstract}
Introduction: Radiotherapy uses high-energy radiation to shrink tumors and kill cancer cells. The radiation may be delivered by a machine outside the body (external-beam radiation therapy), or it may come from radioactive material placed in the body near cancer cells (brachy therapy). Many types of external-beam radiation therapy are delivered using a machine called a linear accelerator (also called a LINAC). The process of commissioning a linac for clinical use includes comprehensive measurements of dosimetric parameters that are necessary to validate the treatment planning systems used to select optimal radiation modality and treatment technique for individual patients. In the present study, clinically pertinent data for both the available photon and electron energies were investigated. Methods: For making measurements in water, a three dimensional radiation field analyzer RFA-300 (Scanditronix Wellhofer) and for absolute dosimetry and other measurements like relative output factors, wedge factors etc., a DOSE1 electrometer (Scanditronix Wellhofer) in a white polystyrene were employed. Results: The percentage depth dose data, wedge factors, output factors and cross beam profiles have been measured and compared with the other studies for photon beams and isodose plots, virtual source to surface distance, uniformity index for electron beams. Conclusion: All these measured data were utilized as input to the ECLIPSE treatment planning system for further clinical use. The characteristics of the electron beams are found to follow the trends experimentally observed by others, generally found to be different from the others theoretically predicted and depend on the model of the machine.
\end{abstract}

Keywords: Commissioning, Radiation field analyzer, Electron beam, Linear accelerator

\section{Introduction}

The Radiotherapy linear accelerator (LINAC) customizes high energy x-rays to conform to a tumor's shape and destroy cancer cells while sparing surrounding normal tissue. It features several built-in safety measures to ensure that it will not deliver a higher dose than prescribed and is routinely checked by the medical physicist to ensure it is working properly [1]. The Clinac-DHX dual photon energy medical linear accelerator manufactured by Varian Associates (Palo Alto, CA) produces five electron beams of nominal energies 6, 9, 12, 16 and $20 \mathrm{MeV}$ along with dual photon energies 6 and $18 \mathrm{MV}$. Since commissioning beam data are treated as a reference and ultimately used by treatment planning systems, it is vitally important

Manuscript received $5^{\text {th }}$ June 2016

Reviewed: $14^{\text {th }}$ June 2016

Author Corrected: $27^{\text {th }}$ June 2016

Accepted for Publication $19^{\text {th }}$ July 2016 that the collected data are of the highest quality to avoid dosimetric and patient treatment errors that may subsequently lead to a poor radiation outcome. Beam data commissioning should be performed with appropriate knowledge and proper tools and should be independent of the person collecting the data [2].

High-energy photon beams from different accelerators of the same nominal energy may have different dosimetric characteristics due to differences in target and flattening filter materials, accelerator guide and collimator designs. Clinically pertinent data for both the available photon energies were measured [3-5].

There are five electron cones made of aluminium with six inserts (low melting alloy) supplied by the manufacturer, which define electron field sizes of $4 \mathrm{x}$ 
4, $6 \times 6,10 \times 10,15 \times 15,20 \times 20$ and $25 \times 25 \mathrm{~cm}^{2}$ at isocenter $(\mathrm{SAD}=100 \mathrm{~cm})$. The electron cone is attached to the machine head using a detachable collimator tray. There would be a gap of $5 \mathrm{~cm}$ from the distal end of the cone to the isocenter. The electron beam characteristics are not similar for all linear accelerators of the same manufacturer and even for the same type of machines
[6-8]. The work has been done to study the characteristics of the photon and electron beam for all the energies and for all field sizes. The characteristics include central axis depth dose, beam profile, isodose plots, virtual source to surface distance, uniformity index and penumbra at nominal source to surface distance (SSD) of $100 \mathrm{~cm}$.

\section{Materials and Methods}

The measurements in water was executed in a three dimensional radiation field analyzer RFA-300 (Scanditronix Wellhofer), using either solid state detectors or RK type ionization chamber were utilized. For absolute dosimetry and other measurements like relative output factors, wedge factors etc., a DOSE1 electrometer (Scanditronix Wellhofer) in a white polystyrene phantom were employed.

The central axis percentage depth doses were measured at $100 \mathrm{~cm} \mathrm{SSD} \mathrm{for} \mathrm{field} \mathrm{sizes} \mathrm{from} 3 \times 3$ to $40 \times 40 \mathrm{~cm}^{2}$. Isodose curves were plotted for the available field sizes up to $35 \times 35 \mathrm{~cm}^{2}$ for open portals and up to the width of $15 \mathrm{~cm}$ for the set of four wedge filters. Isodose plots were drawn using ionization chamber in the RFA system at the source to water level distance of $100 \mathrm{~cm}$. Relative output factors for all possible field sizes were measured using a FC65-G farmer type ionization chamber in a white polystyrene phantom at $\mathrm{d}_{\max }$ relative to the $10 \times 10 \mathrm{~cm}^{2}$ field. Similarly, wedge factors for the four set of physical wedges and for the EDW for both the energies were found out by making measurements for the wedged field and open field at $d_{\max }$ of $1.5 \mathrm{~cm}$ and $3.3 \mathrm{~cm}$ respectively, and taking the ration of these measurements. Field flatness and symmetry of the 6 and $18 \mathrm{MV}$ photon beams were found out by measuring inplane, cross plane and in diagonal plane beam profiles for the depth of $\mathrm{d}_{\max }$ and $10 \mathrm{~cm}$.

The correction factor for perspex tray attenuation was measured by using FC65-G farmer type ionization chamber in a white polystyrene phantom at $10 \mathrm{~cm}$ depth by taking the ratio of meter reading with out and with tray. Block transmission factor was found out by the ratio of fully blocked for a field size of $3 \times 3 \mathrm{~cm}^{2}$ meter reading to the blocking tray alone. Similarly MLC transmission factors found out by closing both A and B bank of MLC's.

For electron dosimetry, a water proof high-doped p-type silicon diode (Scanditronix Wellhofer AB EFD-3G) was used to measure both Percentage depth dose (PDD) and Beam Profile (BP). The diode centre was aligned to the radiation field centre. The thickness of the silicon chip was $0.5 \mathrm{~mm}$ and the diameter of the active area was $2 \mathrm{~mm}$. The nominal source to surface distance of $100 \mathrm{~cm}$ was kept at $0.5 \mathrm{~mm}$ (effective point of measurement) of the diode. The reference diode was mounted in the corner of the electron applicator. Signal gain of the field analyzer unit was adjusted to the level of maximum stability and the speed of the detector movement was kept at its minimum to avoid any back slash. Electron depth dose measurements were measured for six field sizes ranging from $4 \times 4$ to $25 \times 25 \mathrm{~cm}^{2}$ for the six available energies at $\mathrm{SSD}=100 \mathrm{~cm}$. Beam profiles along the central axis were measured in water at the depth of dose maximum with a penumbral margin $5 \mathrm{~cm}$ on both sides for all the field sizes and electron energies. Field flatness and symmetry was measured for all standard applicators at $\mathrm{SSD}=100 \mathrm{~cm}$. All measurements were obtained with the detector always moving form deeper to shallow depth. Isodose curves along the central axis were generated by the Omni Pro Accept software using the PDD and Beam profile data's. The beam profiles measured at six depths $R_{100}, R_{90}, R_{80}{ }^{\prime} R_{50}, R_{p}$ and $R_{t}$ used as a input parameters to generate isodose curves according to the Bently beam model [9].

The characteristic parameters of the electron beam as defined by AAPM Task Group 25's 1990 report [7] and ICRU Report \# 35[1].

1. Range parameters

$\mathrm{R}_{100}=$ Depth of maximum dose.

$\mathrm{R}_{90} \quad=$ Depth of $90 \%$ dose beyond the dose maximum

$\mathrm{R}_{80}=$ Depth of $85 \%$ dose beyond the dose maximum

$\mathrm{R}_{\mathrm{p}}=$ Depth at which the tangent at the $50 \%$ dose point intercepts the extrapolated photon dose: known as the practical range. 
2. Dose along the central axis

The following parameters were first defined by Brahme and Svenssen ${ }^{3}$ and later adopted by ICRU ${ }^{4}$.

$\mathrm{G} \quad=$ normalized dose gradient, the measure of the steepness of the absorbed dose distribution

$\mathrm{D}_{\mathrm{s}} / \mathrm{D}_{\mathrm{m}} \quad=$ ratio of the surface to maximum dose, surface dose is measured at $0.5 \mathrm{~mm}$.

$\mathrm{D}_{\mathrm{x}} / \mathrm{D}_{\mathrm{m}} \quad=$ ratio of the extrapolated photon dose to the dose maximum, the photon background $\mathrm{D}_{\mathrm{x}}$ is defined as an extrapolation of the tail of the absorbed dose distribution back to the practical range.

3. Energy parameters

$\mathrm{E}_{\mathrm{o}} \quad=$ mean beam energy at the surface.

$\mathrm{E}_{\mathrm{p}, \mathrm{o}}=$ most probable beam energy at the surface.

$\mathrm{E}_{\mathrm{o}} \quad=$ single energy value of the electron beam at the surface assuming that the total energy loss in layers traversed by the beam is small ${ }^{5}$.

Range parameters are measured from the central axis depth dose curves and the dosimetric parameters were derived from the isodose plots. Employing the inverse square law method, distances of the virtual source positions ${ }^{8}$ from the isocenter were found out for all the available electron applicators and fields sizes.

\section{Results and discussion}

Photon beams: For $6 \mathrm{MV}$ and $18 \mathrm{MV}$ photons, the ionization ratios were found to be 0.6685 and 0.7810 respectively. The PDD data is presented in Table 1 for $10 \times 10 \mathrm{~cm}^{2}$ field size for $6 \mathrm{MV}$ photons. Comparative PDD data from other studies for $6 \mathrm{MV}$ photon beams [12-16] is also presented in these tables. There is no significant change of PDDs when compared with the similar machines from the same manufacturer. The relative output factors have been shown in Table.2.

Table-1: Percentage depth dose values for 6 MV X-rays from various accelerators, SSD $-100 \mathrm{~cm}$, field size - $10 \mathrm{x}$ $10 \mathrm{~cm}^{2}$

\begin{tabular}{|c|c|c|c|c|c|c|}
\hline \multirow[b]{2}{*}{$\begin{array}{c}\operatorname{Depth}(\mathrm{cm}) \\
\text { in water }\end{array}$} & \multicolumn{6}{|c|}{ Machine } \\
\hline & $\begin{array}{c}\text { Mevatron }^{4} \\
\text { VI }\end{array}$ & $\begin{array}{c}\text { Philips }^{5} \\
\text { SL-25 }\end{array}$ & Leung $^{6}$ & $\begin{array}{c}\text { Clinac }^{7} \\
2500\end{array}$ & BJR $-17^{3}$ & $\begin{array}{c}\text { Present } \\
\text { Study }\end{array}$ \\
\hline 1.5 & 100.0 & 100.0 & 100.0 & 100.0 & 100.0 & 100.0 \\
\hline 2.0 & 99.0 & 99.4 & 99.0 & 98.0 & 98.1 & 99.1 \\
\hline 3.0 & 95.5 & 95.5 & 95.0 & 94.1 & 94.0 & 65.3 \\
\hline 4.0 & 91.5 & 91.5 & 91.0 & 90.4 & 90.8 & 91.2 \\
\hline 5.0 & 87.5 & 87.0 & 86.5 & 86.8 & 87.3 & 86.8 \\
\hline 6.0 & 83.0 & 83.0 & 82.5 & 82.5 & 83.5 & 82.7 \\
\hline 7.0 & 79.0 & 79.2 & 78.5 & 78.4 & 79.2 & 78.5 \\
\hline 8.0 & 75.0 & 75.5 & 74.5 & 74.5 & 75.2 & 74.6 \\
\hline 9.0 & 72.5 & 71.7 & 70.8 & 70.7 & 71.3 & 70.7 \\
\hline 10.0 & 68.5 & 68.1 & 67.0 & 67.0 & 67.7 & 67.1 \\
\hline 11.0 & 65.5 & 64.6 & 63.5 & 63.7 & 64.2 & 63.6 \\
\hline 12.0 & 61.5 & 61.2 & 60.0 & 60.5 & 60.9 & 60.3 \\
\hline 13.0 & 58.0 & 58.0 & 57.0 & 57.4 & 57.8 & 57.1 \\
\hline 14.0 & 55.0 & 55.0 & 54.0 & 54.4 & 54.8 & 54.0 \\
\hline 15.0 & 52.5 & 52.2 & 51.3 & 51.6 & 52.0 & 51.1 \\
\hline 16.0 & 49.0 & 49.3 & 48.5 & 48.8 & 49.4 & 48.2 \\
\hline 17.0 & 46.5 & 46.7 & 46.0 & 46.2 & 46.8 & 45.5 \\
\hline 18.0 & 44.0 & 44.2 & 43.5 & 43.6 & 44.4 & 43.1 \\
\hline 19.0 & 42.0 & 41.9 & 41.3 & 41.2 & 42.1 & 40.6 \\
\hline 20.0 & 40.0 & 39.7 & 39.0 & 38.8 & 40.0 & 38.6 \\
\hline
\end{tabular}


Table-2: Relative output factors for 6 and 18 MV X-rays.

\begin{tabular}{|c|c|c|}
\hline \multirow{2}{*}{ Field Size cm } & \multicolumn{2}{|c|}{ Beam type } \\
\cline { 2 - 3 } & $6 \mathrm{MV}$ & $18 \mathrm{MV}$ \\
\hline $3 \times 3$ & 0.882 & 0.832 \\
\hline $4 \times 4$ & 0.918 & 0.897 \\
\hline $5 \times 5$ & 0.943 & 0.928 \\
\hline $6 \times 6$ & 0.957 & 0.982 \\
\hline $8 \times 8$ & 0.977 & 1.000 \\
\hline $10 \times 10$ & 1.000 & 1.029 \\
\hline $12 \times 12$ & 1.006 & 1.054 \\
\hline $15 \times 15$ & 1.027 & 1.070 \\
\hline $18 \times 18$ & 1.035 & 1.080 \\
\hline $20 \times 20$ & 1.037 & 1.093 \\
\hline $25 \times 25$ & 1.058 & 1.110 \\
\hline $30 \times 30$ & 1.064 & 1.121 \\
\hline $35 \times 35$ & 1.068 & \\
\hline
\end{tabular}

Wedge factors for $18 \mathrm{MV}$ beam were found to be consistently higher than those of $6 \mathrm{MV}$ photons. Wedge angles measured for field sizes of $4 \times 4$ to $15 \times 15 \mathrm{~cm}^{2}$ varied from the nominal values of $15^{\circ}, 30^{\circ}$, and $45^{\circ}$ by $\pm 3^{\circ}$, and for a $60^{\circ}$ wedge the maximum variation was found to be $-7^{\circ}$ for a $4 \times 4 \mathrm{~cm}^{2}$ field of $6 \mathrm{MV}$ photons $[17,18]$.

The cross beam profile for the field size of $6 \times 6 \mathrm{~cm}^{2}, 10 \times 10 \mathrm{~cm}^{2}, 15 \times 15 \mathrm{~cm}^{2}, 20 \times 20 \mathrm{~cm}^{2}$ is shown in Fig.1. for $6 \mathrm{MV} \mathrm{X}-$ rays. The isodose plots are shown in Fig. 2 for the field size of $10 \times 10 \mathrm{~cm}^{2}$.

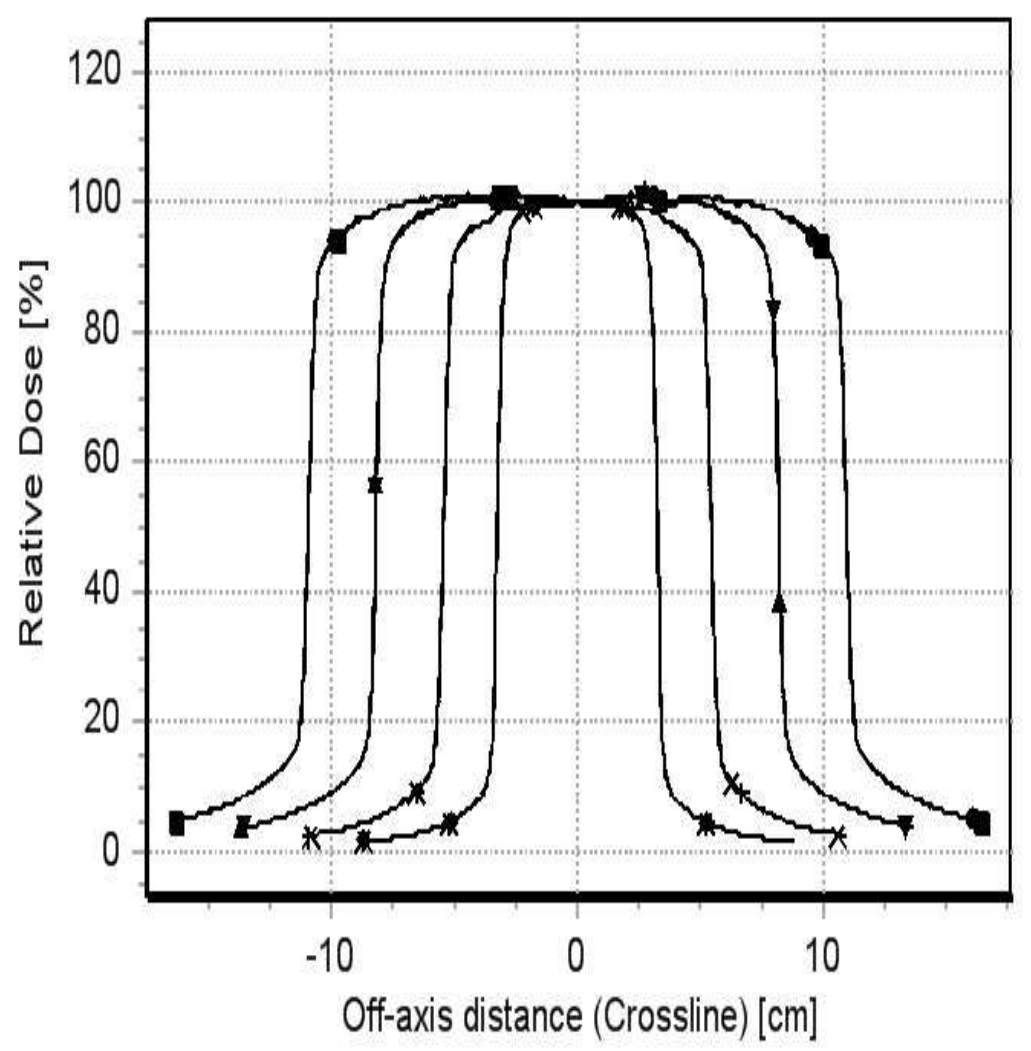

Fig.-1: Cross beam profiles for the field size of $6 \times 6 \mathrm{~cm}^{2}$, $10 \times 10 \mathrm{~cm}^{2}, 15 \times 15 \mathrm{~cm}^{2}, 20 \times 20 \mathrm{~cm}^{2}$ for $6 \mathrm{MV}$ X-rays. 


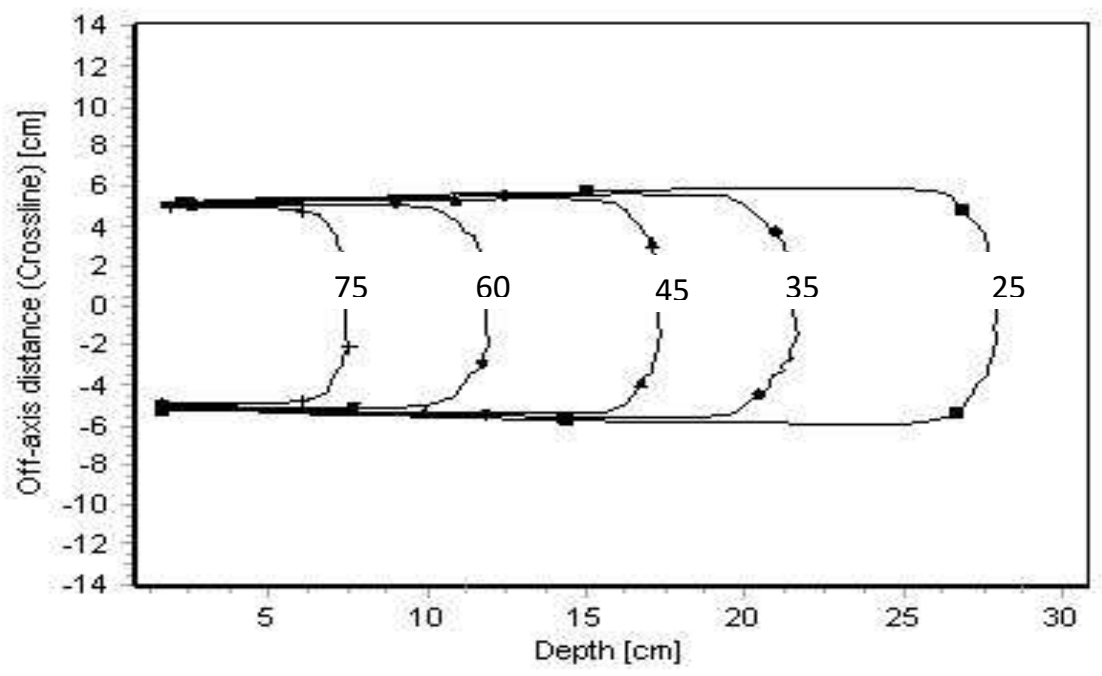

Fig- 2: Isodose plots of $6 \mathrm{MV}$ photon beams for a field size of $10 \times 10 \mathrm{~cm}^{2}$

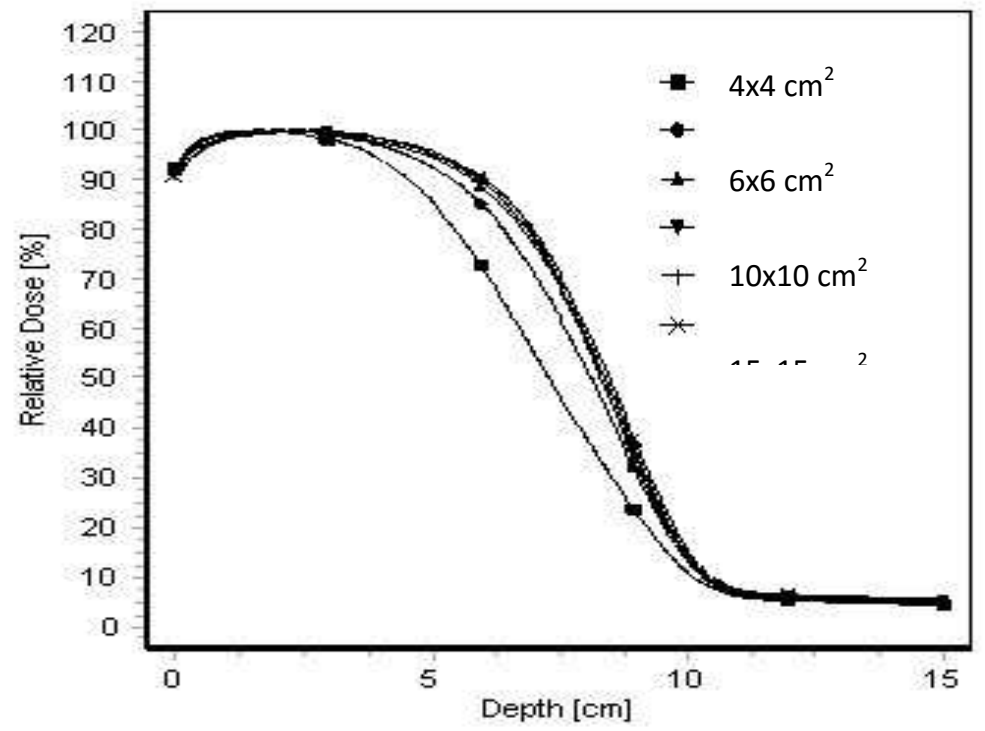

Fig-3: Percentage depth dose curve for a $20 \mathrm{MeV}$ electron beam for various field sizes.

Electron beams: The percentage depth dose curve for a $20 \mathrm{MeV}$ electron beam for the field sizes ranging from $4 \times 4 \mathrm{~cm}^{2}$ to $25 \times 25 \mathrm{~cm}^{2}$ are shown in Fig.3. Derived quantitative depth dose parameters are shown in Table 3 . The central axis depth dose distribution shows a noticeable dependence on the field size, especially for the field sizes smaller than the practical range of that energy. At lower energies the depth dose change was less with decreasing field size than at higher energies. In a narrow beam geometry, most of the incident electrons are scattered out of the central axis and the dose fall's rapidly with depth, as the field size is increased, more electrons are scattered from the edges of the irradiated volume toward the central axis and the depth dose increases gradually with field size, until the field dimensions become comparable to the maximum range of electrons which in practice is represented by $\mathrm{Rp}$.

The range parameters depend on the field size for beam widths smaller than $15 \times 15 \mathrm{~cm}^{2}$ and beam energies higher than 12 $\mathrm{MeV}$, except $\mathrm{R}_{10}$ and $\mathrm{Rp}$. For large field sizes, the range parameters are all independent of the field size and increase with increasing beam energy. The R10 and Rp parameters are increasing function of the beam energy and do not depend on the field size. The flatness and symmetry profiles were evaluated based on International Electrotechnical Commission (IEC) specifications [6]. The value of dose gradient is a good measure of the quality of the beam flattening and 
collimator system. A lower limit of $\mathrm{G}=2.3$ has been suggested for electron beams with mean energy of 5-30 MeV [23, 24]. This criterion was met for all the beam energies from $10 \times 10 \mathrm{~cm}^{2}$ and above field sizes. For $4 \times 4 \mathrm{~cm}^{2}$ field size the value was less for 16 and $20 \mathrm{MeV}$ electron energies. For $6 \times 6 \mathrm{~cm}^{2}$ field size the value was less only for $20 \mathrm{MeV}$ electron energy. For $20 \mathrm{MeV}$ electron energy the value of $\mathrm{G}$ is found to be little less than that of other energies. For smaller beam width $\mathrm{G}$ depends on both beam energy and field size. The smaller value of $\mathrm{G}$ at higher energies may be attributed due to the loss of electronic equilibrium, since the range of these electrons is larger than the field size.

Nominal beam energy supplied by the manufacturer was found to be more consistently near to the most probable energy at the surface (Epo), which was derived from the range-energy relationship. Table 3 contains the values derived from the range parameters for mean energy at the surface (Eo), for the single value of the electron beam at the surface ( $\mathrm{E}_{0}$ ) assuming that the mean energy loss in layers traversed by the beam is small, and the most probable energy at the phantom surface (Epo). The values of the effective source to isocenter distances are shown in Table 4.

Table-3: Characteristic parameters of the Varian Clinac-DHX electron beams $\left({ }^{\mathrm{a}} \pm 0.2 \mathrm{MeV}:{ }^{\mathrm{b}} \pm 0.05 \mathrm{~cm}:{ }^{\mathrm{c}} \pm\right.$ $0.1 \mathrm{~cm}:{ }^{\mathrm{d}} \pm 0.1:{ }^{\mathrm{e}} \pm 1 \%$ )

\begin{tabular}{|c|c|c|c|c|c|c|c|c|c|c|c|}
\hline $\begin{array}{l}\text { Cone } \\
\mathrm{Cm}^{2}\end{array}$ & $\begin{array}{c}\text { Nominal } \\
\text { Energy } \\
\text { MeV }\end{array}$ & $\begin{array}{c}- \\
\mathbf{E}_{\mathbf{o}}^{a} \\
\mathbf{M e V}\end{array}$ & $\begin{array}{c}\mathbf{R}_{\text {ref }}{ }^{b} \\
\mathbf{c m}\end{array}$ & $\begin{array}{c}\mathbf{R 1 0 0}^{\mathrm{c}} \\
\mathrm{cm}\end{array}$ & $\begin{array}{c}\mathbf{R 9 0} \\
\mathbf{C m}\end{array}$ & $\begin{array}{r}\mathbf{R 8 5}^{\mathbf{b}} \\
\mathbf{c m}\end{array}$ & $\begin{array}{r}\mathbf{R 5 0}^{\mathbf{b}} \\
\mathbf{c m}\end{array}$ & $\begin{array}{r}\mathbf{R 1 0}^{\mathrm{b}} \\
\mathrm{cm}\end{array}$ & $\begin{array}{l}\mathbf{R p}^{\mathrm{c}} \\
\mathbf{c m}\end{array}$ & $\begin{array}{c}\mathrm{Ds}^{\mathrm{e}} \\
\%\end{array}$ & $G^{d}$ \\
\hline & 6 & 5.8 & 1.4 & 1.4 & $1 . .9$ & 2.0 & 2.5 & 3.1 & 3.1 & 75.8 & 2.5 \\
\hline & 9 & 8.4 & 2.1 & 2.0 & 2.8 & 2.9 & 3.6 & 4.4 & 4.5 & 82.9 & 2.7 \\
\hline \multirow[t]{5}{*}{$4 \times 4$} & 12 & 11.4 & 2.8 & 2.3 & 3.5 & 3.8 & 4.9 & 6.0 & 6.2 & 88.9 & 2.4 \\
\hline & 16 & 14.2 & 3.6 & 2.1 & 4.1 & 4.5 & 6.1 & 7.9 & 8.1 & 91.9 & 2.0 \\
\hline & 20 & 17.0 & 4.3 & 1.6 & 4.6 & 5.1 & 7.3 & 10.1 & 10.0 & 93.2 & 1.8 \\
\hline & 6 & 5.7 & 1.4 & 1.4 & 1.9 & 2.0 & 2.5 & 3.0 & 3.1 & 75.1 & 2.5 \\
\hline & 9 & 8.5 & 2.1 & 2.2 & 2.9 & 3.0 & 3.6 & 4.4 & 4.4 & 80.0 & 2.8 \\
\hline \multirow[t]{5}{*}{$6 \times 6$} & 12 & 11.8 & 3.0 & 2.8 & 4.0 & 4.2 & 5.1 & 6.1 & 6.1 & 86.1 & 3.0 \\
\hline & 16 & 15.3 & 3.8 & 2.6 & 4.9 & 5.2 & 6.6 & 8.0 & 8.1 & 91.2 & 2.6 \\
\hline & 20 & 18.9 & 4.8 & 1.9 & 5.4 & 6.0 & 8.1 & 10.3 & 10.3 & 93.3 & 2.2 \\
\hline & 6 & 5.6 & 1.4 & 1.3 & 1.8 & 1.9 & 2.4 & 3.0 & 3.0 & 76.2 & 2.6 \\
\hline & 9 & 8.6 & 2.1 & 2.2 & 2.9 & 3.0 & 3.7 & 4.4 & 4.5 & 80.5 & 2.7 \\
\hline \multirow[t]{5}{*}{$10 \times 10$} & 12 & 11.7 & 2.9 & 2.9 & 3.9 & 4.1 & 5.0 & 6.0 & 6.0 & 86.2 & 3.0 \\
\hline & 16 & 15.4 & 3.9 & 3.0 & 5.1 & 5.4 & 6.6 & 8.0 & 8.1 & 91.2 & 2.7 \\
\hline & 20 & 19.3 & 4.9 & 2.0 & 5.8 & 6.4 & 8.3 & 10.3 & 10.1 & 92.8 & 2.7 \\
\hline & 6 & 5.6 & 1.3 & 1.4 & 1.8 & 1.9 & 2.4 & 2.9 & 3.0 & 76.4 & 2.6 \\
\hline & 9 & 8.5 & 2.1 & 2.1 & 2.8 & 2.9 & 3.6 & 4.4 & 4.5 & 81.2 & 2.7 \\
\hline \multirow[t]{5}{*}{$15 \times 15$} & 12 & 11.7 & 2.9 & 2.9 & 4.0 & 4.2 & 5.0 & 6.1 & 6.1 & 86.3 & 2.9 \\
\hline & 16 & 15.5 & 3.9 & 3.0 & 5.1 & 5.4 & 6.6 & 8.0 & 8.0 & 90.8 & 2.9 \\
\hline & 20 & 19.5 & 4.9 & 2.3 & 6.0 & 6.5 & 8.4 & 10.3 & 10.3 & 92.0 & 2.5 \\
\hline & 6 & 5.6 & 1.4 & 1.4 & 1.9 & 2.0 & 2.4 & 3.0 & 2.9 & 77.0 & 2.8 \\
\hline & 9 & 8.6 & 2.1 & 2.2 & 2.9 & 3.0 & 3.7 & 4.5 & 4.5 & 81.3 & 2.8 \\
\hline \multirow[t]{5}{*}{$20 \times 20$} & 12 & 11.9 & 3.0 & 2.9 & 4.0 & 4.2 & 5.1 & 6.2 & 6.1 & 87.4 & 3.0 \\
\hline & 16 & 15.5 & 3.9 & 2.8 & 5.1 & 5.4 & 6.7 & 8.1 & 8.0 & 91.6 & 2.8 \\
\hline & 20 & 19.5 & 4.9 & 2.4 & 6.0 & 6.5 & 8.4 & 10.4 & 10.3 & 92.1 & 2.6 \\
\hline & 6 & 5.7 & 1.4 & 1.4 & 1.9 & 2.0 & 2.5 & 3.0 & 3.0 & 77.3 & 2.7 \\
\hline & 9 & 8.7 & 2.1 & 2.2 & 2.9 & 3.0 & 3.7 & 4.5 & 4.5 & 81.6 & 2.7 \\
\hline \multirow[t]{3}{*}{$25 \times 25$} & 12 & 11.9 & 3.0 & 2.9 & 4.1 & 4.3 & 5.1 & 6.1 & 6.2 & 87.2 & 2.9 \\
\hline & 16 & 15.7 & 4.0 & 3.0 & 5.2 & 5.5 & 6.8 & 8.1 & 8.1 & 90.8 & 2.9 \\
\hline & 20 & 19.7 & 5.0 & 2.7 & 6.1 & 6.6 & 8.5 & 10.5 & 10.3 & 91.2 & 2.6 \\
\hline
\end{tabular}


Table- 4: Effective position of the virtual source from the mechanical isocenter of electron beams from Varian Clinac-DHX linear accelerator

\begin{tabular}{|c|c|c|c|c|c|c|}
\hline \multirow{2}{*}{$\begin{array}{c}\text { Energy } \\
\text { MeV }\end{array}$} & \multicolumn{7}{|c|}{ Virtual source to surface distance } \\
\cline { 2 - 7 } & $\mathbf{4 x 4}$ & $\mathbf{6 x 6}$ & $\mathbf{1 0 x 1 0}$ & $\mathbf{1 5 x 1 5}$ & $\mathbf{2 0 x 2 0}$ & $\mathbf{2 5 x 2 5}$ \\
\hline 6 & 46.29 & 64.81 & 82.59 & 85.79 & 90.02 & 90.84 \\
\hline 9 & 60.59 & 76.15 & 85.49 & 87.39 & 90.45 & 91.54 \\
\hline 12 & 74.69 & 79.87 & 84.83 & 88.23 & 90.25 & 91.56 \\
\hline 16 & 81.06 & 82.30 & 83.38 & 88.67 & 90.39 & 92.35 \\
\hline 20 & 82.24 & 82.99 & 82.67 & 87.53 & 90.62 & 92.60 \\
\hline
\end{tabular}

Isodose curves generated for $6 \mathrm{MeV}$ beam energy for $15 \times 15 \mathrm{~cm}^{2}$ cone was shown in Fig. 4 . At the central axis the curve is flattened and curvature near the field borders. For lower energy beams all the isodose shows some expansion, for the higher energies only the lower isodose bulge out.

The higher isodose level tends to show lateral constriction which becomes worse with decreasing field size. Individual spread of the isodose curves varies depending upon the isodose levels, energy, field size and collimation.

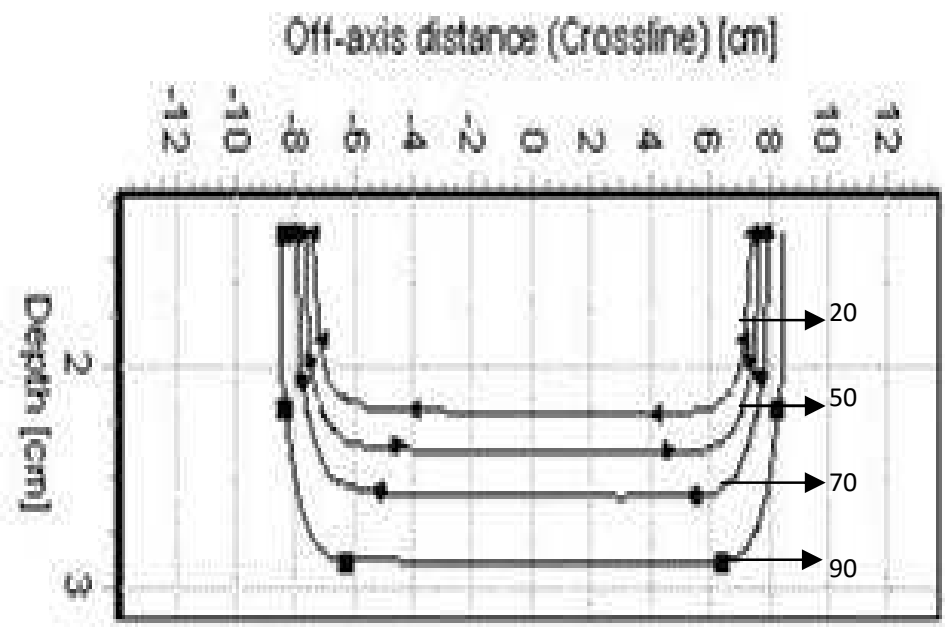

Fig-4: Isodose curves for a $6 \mathrm{MeV}$ electron beam for a $15 \times 15 \mathrm{~cm}^{2}$ field size drawn parallel to the beam axis.

An acceptable lower limit of 0.7 for the uniformity index has been suggested for the therapeutic electron beams with field sizes larger than $10 \times 10 \mathrm{~cm}^{20}$.

The values obtained fulfill the criterion in this case of Clinac DHX beams. For field sizes $4 \times 4 \mathrm{~cm}^{2}$ and $6 \times 6 \mathrm{~cm}^{2}$ the value was found to be between 0.4 and 0.6 .

The results are presented in Table 5. Generally uniformity index increase with increase in field size. The measured penumbra values are shown in Table 6.

The results show that the measured penumbra is almost independent of energy and shown as increasing trend with field size to some extent. The values are in the range of 0.9 to $1.1 \mathrm{~cm}$ [20]. 
Table-5: Flatness and symmetry for the Varian Clinac-DHX electron beams $\left({ }^{a} \leq 2 \% ;^{b} \leq 1 \mathrm{~cm}\right)$

\begin{tabular}{|c|c|c|c|}
\hline Cone & $\begin{array}{c}\text { Nominal energy } \\
\mathrm{MeV}\end{array}$ & $\begin{array}{c}\text { Symmetry }^{\mathrm{a}} \\
\%\end{array}$ & $\begin{array}{c}\text { Flatness }^{\text {b }} \\
\text { cm }\end{array}$ \\
\hline & 6 & 100.2 & 0.79 \\
\hline & 9 & 100.2 & 0.78 \\
\hline \multirow[t]{5}{*}{$4 \times 4$} & 12 & 100.4 & 0.63 \\
\hline & 16 & 100.8 & 0.44 \\
\hline & 20 & 100.1 & 0.28 \\
\hline & 6 & 100.5 & 0.84 \\
\hline & 9 & 100.3 & 0.89 \\
\hline \multirow[t]{5}{*}{$6 \times 6$} & 12 & 100.4 & 0.87 \\
\hline & 16 & 100.5 & 0.55 \\
\hline & 20 & 100.8 & 0.31 \\
\hline & 6 & 101.2 & 0.83 \\
\hline & 9 & 100.6 & 0.81 \\
\hline \multirow[t]{5}{*}{$10 \times 10$} & 12 & 101.2 & 0.91 \\
\hline & 16 & 101.2 & 0.71 \\
\hline & 20 & 101.7 & 0.36 \\
\hline & 6 & 100.6 & 0.82 \\
\hline & 9 & 100.5 & 0.76 \\
\hline \multirow[t]{5}{*}{$15 \times 15$} & 12 & 100.4 & 0.92 \\
\hline & 16 & 100.6 & 0.66 \\
\hline & 20 & 100.6 & 0.36 \\
\hline & 6 & 100.5 & 0.73 \\
\hline & 9 & 100.5 & 0.78 \\
\hline \multirow[t]{5}{*}{$20 \times 20$} & 12 & 100.6 & 0.75 \\
\hline & 16 & 100.6 & 0.52 \\
\hline & 20 & 100.8 & 0.35 \\
\hline & 6 & 100.5 & 0.74 \\
\hline & 9 & 100.8 & 0.89 \\
\hline \multirow[t]{3}{*}{$25 \times 25$} & 12 & 101.2 & 0.82 \\
\hline & 16 & 100.6 & 0.57 \\
\hline & 20 & 101.4 & 0.49 \\
\hline
\end{tabular}

The characteristic parameters derived from the PDD curves are then compared to corresponding values for other Varian accelerators [21, 22]. The field size dependence of depth dose parameters observed by other investigators [21] are also been compared with our results.

The flatness and symmetry evaluated based of IEC specification were met by each electron beam for each applicator size. The values of relative surface dose are with in the range of surface doses reported for other therapy accelerators.

These values are however, higher then those predicted theoretically for broad mono-energetic, mono-directional beams.

This may be because of the energy and angular spread of the primary electrons incident on the phantom surface. 
Table-6: Uniformity index and penumbra for the Clinac-DHX electron beams $\left({ }^{a} \pm 0.05,{ }^{b} \pm 1 \mathrm{~mm}\right)$

\begin{tabular}{|c|c|c|c|}
\hline Cone & $\begin{array}{c}\text { Nominal energy } \\
\mathrm{MeV}\end{array}$ & $\mathbf{U}_{90 / 50}$ & $\begin{array}{c}\mathbf{P}_{80 / 20} \\
\text { cm }\end{array}$ \\
\hline & 6 & 0.37 & 1.09 \\
\hline & 9 & 0.39 & 1.05 \\
\hline \multirow[t]{5}{*}{$4 \times 4$} & 12 & 0.42 & 0.98 \\
\hline & 16 & 0.43 & 0.94 \\
\hline & 20 & 0.43 & 0.91 \\
\hline & 6 & 0.47 & 1.10 \\
\hline & 9 & 0.51 & 1.04 \\
\hline \multirow[t]{5}{*}{$6 \times 6$} & 12 & 0.52 & 1.03 \\
\hline & 16 & 0.54 & 1.02 \\
\hline & 20 & 0.56 & 1.02 \\
\hline & 6 & 0.66 & 1.16 \\
\hline & 9 & 0.69 & 1.09 \\
\hline \multirow[t]{5}{*}{$10 \times 10$} & 12 & 0.68 & 1.09 \\
\hline & 16 & 0.69 & 1.11 \\
\hline & 20 & 0.68 & 1.11 \\
\hline & 6 & 0.75 & 1.10 \\
\hline & 9 & 0.79 & 1.00 \\
\hline \multirow[t]{5}{*}{$15 \times 15$} & 12 & 0.77 & 1.05 \\
\hline & 16 & 0.79 & 1.11 \\
\hline & 20 & 0.79 & 1.11 \\
\hline & 6 & 0.80 & 1.18 \\
\hline & 9 & 0.84 & 1.13 \\
\hline \multirow[t]{3}{*}{$20 \times 20$} & 12 & 0.85 & 1.11 \\
\hline & 16 & 0.85 & 1.08 \\
\hline & 20 & 0.84 & 1.09 \\
\hline
\end{tabular}

Summary: Clinically pertinent data for the photon and electron beams from the Clinac- DHX were measured and compared with similar beams available on other units. The central axis depth dose data are comparable to the averaged data of BJR supplement 17 for 6 and 18 MV X-rays, perhaps because of the use of the same material in the target and flattening filter in these accelerators. Wedge angles do not match with the specified angles, especially in the case of larger angle wedges, perhaps due to the beam flatness, whish changes with the increasing field from middle trump to outer horns.

These results may be helpful in bringing home the point that the beams even from the same type of machines may be quite different and individualized measurements must be carried out for each of the available energies from each such unit. All these measured data were utilized as input to the ECLIPSE treatment planning system for the clinical use.

The characteristics of the electron beams are found to follow the trends experimentally observed by others, generally found to be different from the others theoretically predicted and depend on the model of the machine.

The uniformity index, penumbra, flatness and symmetry are well within the limits except for smaller field sizes. Thus the electron beam characteristics may vary from machine to machine and must be ascertained individually. 
Funding: Nil, Conflict of interest: None initiated. Permission from IRB: Yes

\section{References}

1. International Commission on Radiation Units and Measurements (ICRU). Report No. 35. ICRU Publication. B ethesda. MD: 1984.

2. International Commission on Radiation Units and Measurements (ICRU). Report No. 21. ICRU Publication. Bethesda. MD: 1972.

3. Central axis depth dose data for use in radiotherapy. A survey of depth doses and related data measured in water or equivalent media. $\mathrm{Br} \mathrm{J}$ Radiol Suppl. 1983;17:1-147.

4. Horton JL. Dosimetry of the Siemens Mevatron 67 linear accelerator. Int J Radiat Oncol Biol Phys. 1983 Aug;9(8):1217-23.

5. Palta JR, Ayyangar K, Daftari I, Suntharalingam N. Characteristics of photon beams from Philips SL25 linear accelerators. Med Phys.1990 Jan-Feb;17(1):10616

6. Brahme A, Svensson H. Specification of electron beam quality from the central-axis depth absorbed-dose distribution. Med Phys. 1976 Mar-Apr;3(2):95-102.

7. Khan FM, Doppke KP, Hogstrom KR, Kutcher GJ, Nath R, Prasad SC, Purdy JA, Rozenfeld M, Werner BL. Clinical electron-beam dosimetry: report of AAPM Radiation Therapy Committee Task Group No. 25. Med Phys. 1991 Jan-Feb;18(1):73-109.

8. International Electrotechnical Commission, Report 35-I and 35-II, Medical electrical equipment, Medical Electron Accelerator, Section IV: Functional performance characteristics and report, 1984.

9. Almond P. R. Proceedings of the symposium on electron beam therapy, Sloan- Kettering, Ny. 43-53, 1981.

10. Milan J, Bentley RE. The storage and manipulation of radiation dose data in a small digital computer. Br J Radiol. 1974 Feb;47(554):115-21.

11. Procedures in external radiation therapy dosimetry with electron and photon beams with maximum energies between 1 and $50 \mathrm{MeV}$. Recommendations by the Nordic Association of Clinical Physics (NACP). Acta Radiol Oncol. 1980;19(1):55-79.

12. Sharma AK, Supe SS, Anantha N, Subbarangaiah K. Physical characteristics of photon and electron beams from a dual energy linear accelerator. Med Dosim. 1995 Spring;20(1):55-66.

13. Jamshidi A, Kuchnir FT, Reft CS. Determination of the source position for the electron beams from a highenergy linear accelerator. Med Phys. 1986 Nov-Dec; 13(6):942-8.

14. Leung PMK. The physical basis of radiotherapy. Lecture Notes. Ontario cancer institute Publication. $1978 ; \mathrm{P}-17$.

15. Barnes WH, Hammond DB, Janik GG. Beam characteristics of the Clinac-2500. Proceedings of the $9^{\text {th }}$ Varian users meeting, South Carolina. 1982; 36-39.

16. Findley DO, Forell BW, Wong PS. Dosimetry of a dual photon energy linear accelerator. Med Phys. 1987 Mar-Apr;14(2):270-3.

17. Ikoro NC, Johnson DA, Antich PP. Characteristics of the 6-MV photon beam produced by a dual energy linear accelerator. Med Phys. 1987 Jan - Feb; 14 (1) : 93-7.

18. Palta JR, Meyer JA, Hogstrom KR. Dosimetric characterization of the 18-MV photon beam from the Siemens Mevatron 77 linear accelerator. Med Phys. 1984 Sep-Oct;11(5):717-24.

19. Patterson MS, Sharrage PC. Characteristics of 18 MV photon beam from a Therac 20 linear accelerator. Med. Phys. 1981; 8: 217-228.

20. Johnson DA, Ikoro NC, Chang $\mathrm{CH}$, Scarbrough EC, Antich PP. Properties of the 18-MV photon beam from a dual energy linear accelerator. Med Phys. 1987 NovDec;14(6):1071-8.

21. Radiation oncology physics: a handbook for teachers and students, IAEA, Vienna, 2005; 196 - 197.

22. International Electrotechnical Commission, Report 35 - I and 35-II, Medical electrical equipment, Medical Electron Accelerator, Section IV: Functional performance characteristics and report, 1984. 
23. Jamshidi A, Kuchnir FT, Reft CS. Characteristic parameters of 6-22 MeV electron beams from a 25$\mathrm{MeV}$ linear accelerator. Med Phys. 1987 MarApr;14(2):282-8.
24. Kirby TH, Gastorf RJ, Hanson WF, Berkley LW, Gagnon WF, Hazle JD, Shalek RJ. Electron beam central axis depth dose measurements. Med Phys. 1985 May-Jun;12(3):357-61

\section{How to cite this article?}

Varatharaj C, Shwetha B, Rekha Reddy B, Ravikumar M, S. Sathiyan, Ganesh K. M. Physical characteristics of photon and electron beams from a radiotherapy accelerator. Int J Med Res Rev 2016;4 (7):11781188.doi:10.17511/ijmrr.2016.i07.18. 